\title{
The impact of frailty on outcomes after cardiac surgery: A systematic review
}

\author{
Aresh Sepehri, BSc, ${ }^{\text {a }}$ Thomas Beggs, ${ }^{\mathrm{b}}$ Ansar Hassan, MD, PhD, FRCSC, ${ }^{c}$ \\ Claudio Rigatto, MD, MSc, FRCPC, ${ }^{\text {,e }}$ Christine Shaw-Daigle, BA, MLS, AHIP, \\ Navdeep Tangri, MD, PhD, FRCPC, ${ }^{\text {d,e }}$ and Rakesh C. Arora, MD, PhD, FRCSC, FACS ${ }^{g}$
}

Objective: Current preoperative assessments for cardiac surgery, such as the European System for Cardiac
Operative Risk Evaluation II and the Society of Thoracic Surgeons risk score, are limited in their ability to pre-
dict postoperative outcomes. This is thought to be due to the reliance on chronological age as a predictor of
health. In geriatrics, frailty assessments have been developed as a tool in determining physiologic functioning
capacity. Whether or not frailty predicts postoperative outcomes independent of existing cardiac preoperative
risk scores remains unknown.

\begin{abstract}
Methods: We performed a systematic review to determine the association of frailty with negative postoperative outcomes such as major adverse cardiac and cerebrovascular events (MACCE) in patients undergoing cardiac surgery. We searched PubMed, EMBASE, the Cochrane library, and Ageline from inception until July 2013 and screened 5913 abstracts for potential inclusion. Of these, 6 studies examined the relationship between objective frailty assessments and postoperative outcomes. Our included studies evaluated 4756 patients undergoing cardiac surgery.
\end{abstract}

Results: Frailty, defined using multiple criteria, had a strong positive relationship with the risk of MACCE (odds ratio, 4.89; 95\% confidence interval, 1.64-14.60). Relationships were stronger in older patients undergoing transcatheter aortic valve replacement (TAVR) than younger patients undergoing coronary artery bypass grafting and valvular surgery (hazard ratio for frailty in TAVR, 3.31-4.89 vs hazard ratio for non-TAVR, 1.10-3.16).

Conclusions: Patients deemed frail, determined using an objective assessment tool, have a higher likelihood of experiencing mortality, morbidity, functional decline, and MACCE following cardiac surgery, regardless of definition. Further study is needed to determine which components of frailty are most predictive of negative postoperative outcomes before integration in risk prediction scores. (J Thorac Cardiovasc Surg 2014;148:3110-7)

See related commentary on pages $3117-8$.

In the current era of cardiac surgery, more than half of procedures are being performed in patients aged 75 years and older. ${ }^{1}$ These elderly and often frail patients represent the

From the Faculty of Medicine, ${ }^{a}$ University of British Columbia, Vancouver, British Columbia, Canada; School of Medicine, ${ }^{\mathrm{b}}$ Royal College of Surgeons in Ireland, Dublin, Ireland; Faculty of Medicine, ${ }^{\mathrm{c}}$ Dalhousie University, Halifax, Nova Scotia, Canada; Renal Program, ${ }^{\mathrm{d}}$ Seven Oaks General Hospital, Winnipeg, Manitoba, Canada; Section of Nephrology, ${ }^{\mathrm{e}}$ Department of Medicine, University of Manitoba, Winnipeg, Manitoba, Canada; St Boniface General Hospital, ${ }^{\mathrm{f}}$ Winnipeg, Manitoba, Canada; and University of Manitoba Health Sciences Libraries, ${ }^{\mathrm{g}}$ Winnipeg, Manitoba, Canada

Disclosures: Rakesh C. Arora has an unrestricted educational grant from Pfizer Canada, Inc, for work unrelated to the material presented here. Navdeep Tangri is supported by a KRESCENT New Investigator Award and an Manitoba Health Research Council Establishment Award. All other authors have nothing to disclose with regard to commercial support.

Aresh Sepehri and Thomas Beggs are co-first authors and Navdeep Tangri and Rakesh C. Arora are co-senior authors.

Received for publication March 21, 2014; revisions received June 23, 2014; accepted for publication July 14, 2014; available ahead of print Sept 4, 2014.

Address for reprints: Rakesh C. Arora, MD, PhD, FRCSC, FACS, St Boniface Hospital/I.H. Asper Institute, CR3012-369 Tache Ave, Winnipeg, Manitoba, Canada R2H 2A6 (E-mail: rakeshcarora@gmail.com).

$0022-5223 / \$ 36.00$

Copyright (c) 2014 by The American Association for Thoracic Surgery

http://dx.doi.org/10.1016/j.jtcvs.2014.07.087 fastest growing demographic in North America ${ }^{2}$ and are at increased risk of falls, prolonged hospitalization, and mortality after surgery. ${ }^{3}$ A comprehensive preoperative assessment is essential to determine the relative risk and benefit of the surgical intervention in this patient population. The European System for Cardiac Operative Risk Evaluation (EuroSCORE) II and Society of Thoracic Surgeons (STS) risk scores are widely used to evaluate perioperative mortality and morbidity in patients undergoing cardiac surgery. ${ }^{4,5}$ These risk assessment methods have limitations. The EuroSCORE II typically overestimates perioperative risk, ${ }^{5}$ whereas the STS score, which is considered to be the global standard, ${ }^{3,6}$ has been reported to underestimate perioperative risk in frail patients. ${ }^{3,7}$

The limitations of these risk models may be tied to their weighting of chronological age and medical diagnoses without a standardized and/or comprehensive evaluation of the biological status of an elderly patient. ${ }^{3,8}$ The realization that age is not synonymous with vulnerability to adverse health outcomes has led to the development of the concept of frailty. Frailty is an umbrella term that encompasses the patient factors of malnutrition, wasting, weakness, slowness, and inactivity. Although frailty tends to increase with age, its assessment, measured through a 


\section{Abbreviations and Acronyms \\ $\mathrm{CABG}=$ coronary artery bypass graft \\ EuroSCORE $=$ European System for Cardiac \\ Operative Risk Evaluation \\ MACCE = major adverse cardiac and cerebrovascular events \\ STS $=$ Society of Thoracic Surgeons \\ TAVR $=$ transcatheter aortic valve repair}

variety of physical and cognitive tests, nutritional status, and self-reported functional deterioration, ${ }^{9}$ is independent of age or any specific medical condition. ${ }^{3}$ It can be thought of as a measure of an individual's vulnerability due to an inability to maintain homeostasis, ${ }^{10}$ where small insults, such as minor infections or surgeries, can have a disproportionate influence on health. Frailty has been linked to cardiovascular disease ${ }^{11}$ and increased mortality and morbidity in the general population. ${ }^{12}$

To examine the effect of frailty on surgical outcomes, we performed a systematic review of relevant studies examining the association of frailty with major adverse cardiac and cerebrovascular events (MACCE) in patients undergoing cardiac surgery. We hypothesized that patients deemed frail by objective criteria would have a higher risk of MACCE after undergoing cardiac surgery. We also hypothesized that specific components (or domains) of the frailty assessment, may be more strongly associated with MACCE than others.

\section{METHODS}

\section{Data Sources and Search Strategy}

We aimed to systematically identify observational studies of human beings that explored the link between frailty, cardiac surgery, and postoperative outcomes. The primary question of interest was whether or not frailty demonstrated predictive value when determining risk of adverse outcomes following coronary artery bypass graft (CABG) and/or valve procedures. In collaboration with 2 medical librarians (K.M. and C.S.D.), a search strategy was designed and implemented to capture all relevant studies from the available literature. The following electronic databases were searched from their date of establishment to July 2013: PubMed, Cochrane library, Ageline, and EMBASE. The search strategy was tailored to each database and used a combination of key words, including frailty, elderly, and cardiac surgery, as well as medical subject headings terms. The reference lists from any relevant review articles were cross-matched with the search results to ensure the search terms were broad and inclusive of all relevant studies, reducing the possibility of missing studies. The search resulted in 5913 articles.

\section{Article Eligibility and Selection Criteria}

From the 5913 articles 2 reviewers (A.S. and T.B.) selected 40 full-text citations for text review based on the title and abstract (Figure 1). To be included in the systematic review studies had to meet several inclusion criteria. First, frailty measurements needed to be based on comprehensive assessments of frailty, rather than on individual domains of frailty such as handgrip strength. Second, clear outcomes had to be measured. Finally, only studies that were based on a cardiac surgery population were included. Studies were finalized for inclusion in the systematic review after discussion with a third reviewer (N.T.). Disagreements were resolved by consensus.

\section{Data Extraction}

One reviewer (A.S.) conducted the data extraction, collecting the comparable and relevant information. Data extraction was then verified by a second reviewer (T.B.).

\section{Evaluation of Risk of Bias}

We evaluated each study for risk of bias using the Newcastle-Ottawa Scale $^{13}$ to assess its quality (Table 1). The Newcastle-Ottawa Scale is a quality evaluation method for nonrandomized studies. Newcastle-Ottawa Scale criteria are split into 3 sections: selection, comparability, and outcome. Each study is designated a number of stars for each section, based on predetermined queries.

\section{Statistical Analysis}

Because of significant clinical heterogeneity in the patient population, definitions of frailty, study methodologies, and covariate adjustment were encountered; meta-analysis was not performed.

\section{RESULTS}

\section{Study Characteristics}

The individual study characteristics are outlined in Table 2. The 6 studies each looked at the relationship between frailty and postoperative outcomes for patients undergoing cardiac surgery. The cardiac surgeries included CABG, valve replacement, and transcatheter aortic valve replacement (TAVR). In total, the studies encompassed 4756 patients. Three of the studies were conducted in the United States and/or Canada and the remaining studies were conducted in Europe. All the studies were prospective and published after 2010. They each provided a definition and list of criteria for determining frailty. Each study also defined its own primary outcomes.

\section{Measures of Frailty and Physical Function}

Each study used different definitions of frailty, as outlined in Table 3. This resulted in varying methods for identification of frailty and physical function, based on currently accepted measurements. For example, in an American study looking at TAVR $^{3}$ investigators used a modified Fried Scale, whereas a European study ${ }^{14}$ created an assessment using certain domains from previous assessments shown to have predictive value, which they referred to as the simplified Comprehensive Assessment of Frailty. Two studies ${ }^{14,15}$ used a modified geriatric baseline examination, whereas another looked at the Katz Index of Independence in Activities of Daily Living, independence in ambulation, and previous diagnosis of dementia. ${ }^{16}$ Afilalo and colleagues $^{2}$ looked at 4 scales for comparison. Frailty criteria for all the studies were determined through questionnaires, physical function tests, and lab investigations.

Four studies ${ }^{3,14-16}$ looked at frailty on a linear scale. Each study also dichotomized the data, creating a point on the scale that could definitively label patients as frail or not frail. The frailty measurements in the remaining 2 


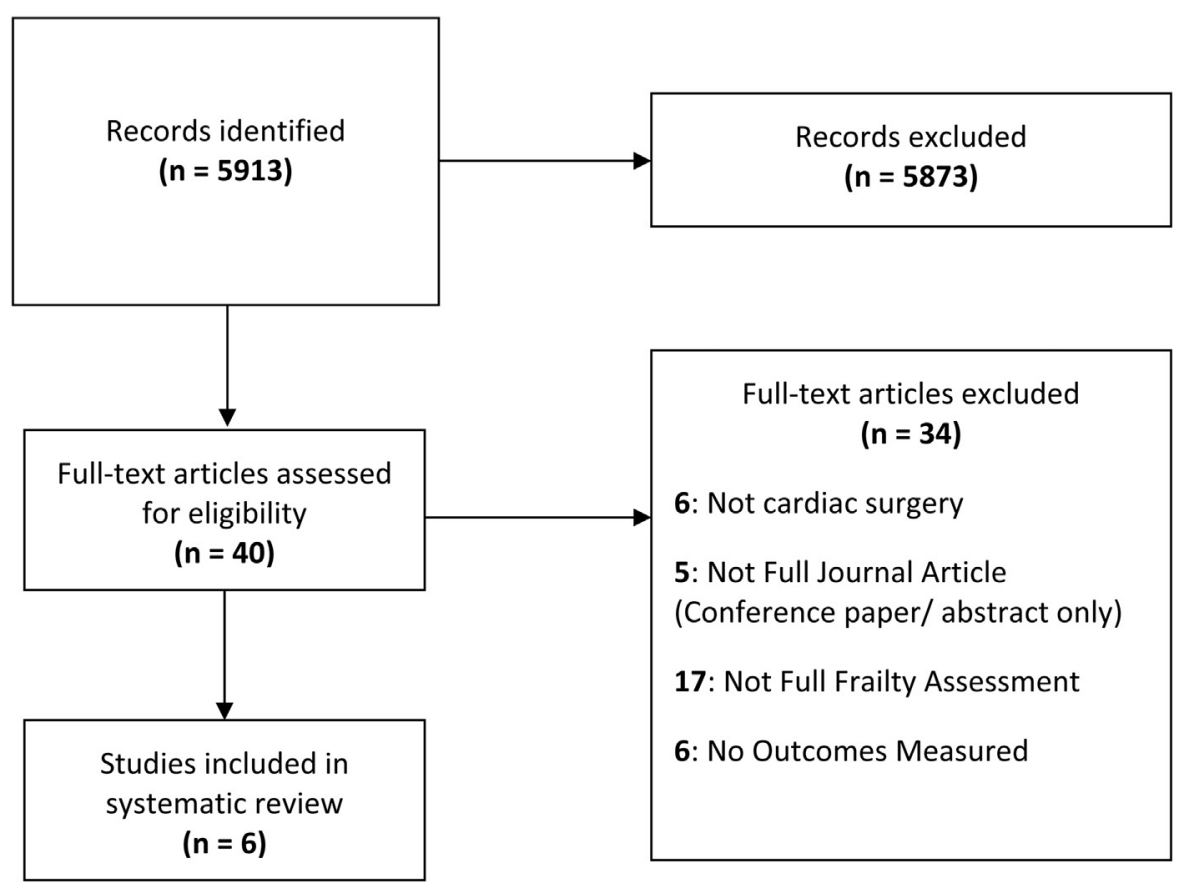

FIGURE 1. Flow diagram of reviewed studies.

studies ${ }^{2,17}$ were defined to determine either the presence or lack of frailty and did not have a correlating scale.

\section{Association of Frailty With Postoperative Outcomes in Patients Undergoing Cardiac Surgery}

All 6 published studies related frailty in patients undergoing cardiac surgery to an adverse clinical outcome (Table 4). A Canadian study ${ }^{17}$ looked at all-cause midterm mortality after cardiac surgery and defined frailty as any impairment in activities of daily living or ambulation, or a history of dementia. The study determined that patients who were deemed frail had a 1.5-fold higher risk of mortality compared with patients who were not frail (hazard ratio, 1.5; 95\% confidence interval [CI], 1.1-2.2). The European study using their Comprehensive Assessment of Frailty definition ${ }^{14}$ found similar results, showing a relation between frailty and an increased 1-year mortality rate following cardiac surgery (odds ratio [OR], 1.097; 95\% CI, 1.038-1.160).

Three studies examined the relationship between frailty and outcomes after TAVR. Two studies used a modified

TABLE 1. Newcastle-Ottawa Scale quality evaluations

\begin{tabular}{lcccc}
\hline First author, year & Selection & Comparability & Outcome & Total \\
\hline Lee, 2010 & 3 & 0 & 2 & 5 \\
Sundermann, 2011 & 4 & 1 & 1 & 6 \\
Afilalo, 2012 & 3 & 1 & 2 & 6 \\
Green, 2012 & 3 & 1 & 3 & 7 \\
Stortecky, 2012 & 3 & 1 & 2 & 6 \\
Schoenenberger, 2013 & 3 & 1 & 1 & 5 \\
\hline
\end{tabular}

Multidimensional Geriatric Assessment for determining frailty. ${ }^{15,16}$ Both studies had parallel results, with 1 study $^{15}$ finding a significant association between frailty and functional decline (OR, 4.46; 95\% CI, 1.85-10.75) and the other ${ }^{16}$ showing an association between frailty and increased mortality rates (OR, 3.68; 95\% CI, 1.21 11.19). In line with these 2 studies, the Canadian study looking at $\mathrm{TAVR}^{3}$ found that using a modified Fried Scale, patients deemed frail had a more than 3-fold higher risk of mortality when compared with patients not deemed frail (hazard ratio, 3.16; 95\% CI, 1.33-7.51).

Afilalo and colleagues ${ }^{2}$ looked at 4 different scales to determine frailty: the 5-item Cardiovascular Health Study Frailty Scale, 7-item expanded Cardiovascular Health Study Frailty Scale, 4-item MacArthur Study of Successful Aging, and gait speed. The study looked at each scale independently when determining a patient's frailty. When looking for an association between the presence of frailty and mortality/major morbidity after CABG and/or valve surgery, it was found that only gait speed was significant (OR, 2.63; 95\% CI, 1.17-5.90).

It is interesting to note that in patients undergoing traditional procedures such as $\mathrm{CABG}$ and/or valve procedures, frailty was associated with an increased OR of mortality ranging from 1.10 to 2.63 , whereas in patients being referred for less invasive procedures such as TAVR, frailty was shown to be associated with a 3- to 5-fold increase in mortality, MACCE, or functional decline. One would speculate that the less invasive transcatheter aortic valve implantation procedure would result in better outcomes 
TABLE 2. Characteristics of included studies

\begin{tabular}{|c|c|c|c|c|c|}
\hline First author, year & Population & $\mathbf{n}^{*}$ & Frailty measurement & Outcomes measured & Association \\
\hline Lee, 2010 & $\begin{array}{l}\text { Patients undergoing cardiac } \\
\text { surgery }\end{array}$ & 3826 & $\begin{array}{l}\text { Katz Index of Independence } \\
\text { in Activities of Daily } \\
\text { Living, independence in } \\
\text { ambulation, and previous } \\
\text { diagnosis of dementia }\end{array}$ & $\begin{array}{l}\text { In-hospital mortality, } \\
\text { midterm all-cause } \\
\text { mortality, discharge to an } \\
\text { institution, and secondary } \\
\text { in-hospital outcomes }\end{array}$ & $\begin{array}{l}\text { Frailty was linked to } \\
\text { increased unadjusted in- } \\
\text { hospital outcomes, } \\
\text { increased in-hospital } \\
\text { mortality, increased } \\
\text { institutional discharge, and } \\
\text { reduced midterm survival }\end{array}$ \\
\hline Sundermann, 2011 & $\begin{array}{l}\text { Patients } \geq 74 \text { y undergoing } \\
\text { cardiac surgery }\end{array}$ & 400 & Simplified CAF & $\begin{array}{l}\text { 1-y all-cause mortality, and } \\
\text { MACCE }\end{array}$ & $\begin{array}{l}\text { Frailty showed a good } \\
\text { predictive ability } \\
\text { concerning } 1-y \text { mortality }\end{array}$ \\
\hline Afilalo, 2012 & $\begin{array}{l}\text { Patients } \geq 70 \text { y undergoing } \\
\text { CABG and/or valve } \\
\text { surgery }\end{array}$ & 152 & $\begin{array}{l}4 \text { scales used: } \\
\text { 5-item CHS } \\
\text { 7-item expanded CHS } \\
\text { 4-item MSSA } \\
\text { Gait speed }\end{array}$ & $\begin{array}{l}\text { Postoperative mortality or } \\
\text { major morbidity }\end{array}$ & $\begin{array}{l}\text { Only frailty measured } \\
\text { through gait speed showed } \\
\text { a statistically significant } \\
\text { association with an } \\
\text { increased mortality or } \\
\text { major morbidity }\end{array}$ \\
\hline Green, 2012 & $\begin{array}{l}\text { Patients } \geq 60 \text { y with } \\
\text { advanced aortic disease } \\
\text { undergoing TAVR }\end{array}$ & 159 & $\begin{array}{l}\text { Modified Fried Frailty } \\
\text { Criteria }\end{array}$ & $\begin{array}{l}\text { All-cause mortality, and } \\
\text { procedural outcomes }\end{array}$ & $\begin{array}{l}\text { Frailty was independently } \\
\text { associated with reduced } \\
\text { long-term survival after } \\
\text { TAVR }\end{array}$ \\
\hline Stortecky, 2012 & $\begin{array}{l}\text { Patients } \geq 70 \text { y undergoing } \\
\text { TAVI }\end{array}$ & 100 & $\begin{array}{l}\text { Modified Multidimensional } \\
\text { Geriatric Assessment }\end{array}$ & $\begin{array}{l}\text { All-cause mortality, and } \\
\text { MACCE }\end{array}$ & $\begin{array}{l}\text { Strong evidence for an } \\
\text { association between the } \\
\text { frailty index with all-cause } \\
\text { mortality and MACCE at } 1 \\
\text { y post-TAVI }\end{array}$ \\
\hline Schoenenberger, 2013 & $\begin{array}{l}\text { Patients } \geq 70 \text { y undergoing } \\
\text { TAVI }\end{array}$ & 119 & $\begin{array}{l}\text { Modified Geriatric Baseline } \\
\text { Examination }\end{array}$ & $\begin{array}{l}\text { Functional decline, and } \\
\text { functional decline or death }\end{array}$ & $\begin{array}{l}\text { Frailty index was strongly } \\
\text { associated with functional } \\
\text { decline as well as mortality }\end{array}$ \\
\hline
\end{tabular}

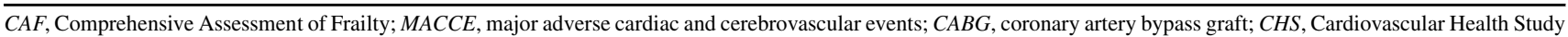
Frailty Scale; MSSA, MacArthur Study of Successful Aging; TAVR, transcatheter aortic valve repair; TAVI, transcatheter aortic valve implantation. *Study sample size.

for patients. However transcatheter aortic valve implantation is used to treat severe aortic stenosis and is reserved for older patients who are deemed inoperable. ${ }^{15}$ In the studies investigating TAVR and frailty, patients were older and had increased EuroSCOREs, which may account for the increase in the hazard ratios and ORs. ${ }^{15,16}$ Patients who are undergoing TAVR are typically selected with the notion that they would not fair well with a conventional surgical aortic valve replacement. ${ }^{3}$ This could lead to a discrepancy when trying to apply the studies findings to those in a lower risk demographic. ${ }^{3}$

\section{Risk of Bias}

The 6 studies had a similar risk of bias. All the studies have a relatively low risk of bias in the selection domains, but had a higher risk of bias in comparability. The risk of bias in outcome varied between studies.

\section{DISCUSSION}

In our systematic review, multiple studies identified a relationship between frailty and adverse postoperative outcomes following cardiac surgery. Although several assessments (ie, definitions) of frailty were used (Table 3), these studies universally demonstrated that patients classified as being frail had a higher likelihood of experiencing mortality, morbidity, functional decline, and MACCE.

To our knowledge, our systematic review is the first to evaluate a range of frailty assessments and their relationship to adverse postoperative outcomes following cardiac surgery. A relevant systematic review was published in 2009 and examined the relationship between frailty and cardiovascular disease. ${ }^{5}$ Although this review was different from ours, both reviews shared similarities in that both used a comprehensive and clear assessment of frailty criteria. Together our results support our conclusion that frailty has an influence on mortality in operative or nonoperative patients with cardiovascular disease. ${ }^{5}$

Our review highlights some important similarities between the frailty assessments. Five studies incorporated a physical function assessment as part of the determination of frailty, including handgrip strength, Timed Up and Go test, gait speed, and climbing up stairs. Poor results in these physical function tests, in particular gait speed and handgrip strength, can be indicative of sarcopenia, ${ }^{18}$ which is defined as muscle loss independent of inflammation or disease. ${ }^{19,20}$ Previous studies have already linked 
TABLE 3. Frailty criteria

\begin{tabular}{|c|c|c|c|}
\hline $\begin{array}{c}\text { First author, } \\
\text { year }\end{array}$ & Frailty measurement & Measurement method & Criteria for frailty \\
\hline Lee, 2010 & $\begin{array}{l}\text { Katz Index of Independence in } \\
\text { Activities of Daily Living, } \\
\text { independence in ambulation, } \\
\text { and previous diagnosis of dementia }\end{array}$ & $\begin{array}{l}\text { - Dependence in feeding, bathing, dressing, } \\
\text { transferring, and toileting } \\
\text { - Urinary incontinence } \\
\text { - Walking aid or assist required } \\
\text { - Previous diagnosis of dementia }\end{array}$ & $\begin{array}{l}\text { Defined as frail if any of the frailty elements } \\
\text { were present }\end{array}$ \\
\hline Sundermann, 2011 & Simplified CAF & $\begin{array}{l}\text { - Prolonged time for a patient to get up and } \\
\text { down from a chair } 3 \text { times } \\
\text { - Self-reported weakness } \\
\text { - Patient is asked to climb as many stairs as } \\
\text { they are able } \\
\text { - Two physicians ( } 1 \text { being the cardiac surgeon) } \\
\text { conduct a Clinical Frailty Scale as outlined } \\
\text { by the Canadian Study of Health and Aging } \\
\text { - High serum creatinine level }\end{array}$ & $\begin{array}{l}\text { Results from the CAF scores are tabulated into } \\
\text { a scale from } 1 \text { to } 35 \text { points as outlined by the } \\
\text { supplementary CAF Test Sheet. Scores } \\
\text { between } 1 \text { and } 10 \text { are deemed not frail, } \\
\text { between } 11 \text { and } 25 \text { are deemed moderately } \\
\text { frail, and between } 26 \text { and } 36 \text { are deemed } \\
\text { severely frail }\end{array}$ \\
\hline Afilalo, 2012 & $\begin{array}{l}4 \text { scales used: } \\
\text { 5-item CHS } \\
\text { 7-item expanded CHS } \\
\text { 4-item MSSA } \\
\text { Gait speed }\end{array}$ & $\begin{array}{l}\text { - 5-item CHS used gait speed, handgrip } \\
\text { strength, inactivity, exhaustion, and weight } \\
\text { loss } \\
\text { - } 7 \text {-item CHS used the above as well as } \\
\text { cognitive impairment and depressed mood } \\
\text { - } 4 \text {-item MSSA used gait speed, handgrip } \\
\text { strength, inactivity, and cognitive } \\
\text { impairment } \\
\text { - prolonged time for gait speed test ( } \geq 6 \mathrm{sec} \text { to } \\
\text { walk } 5 \mathrm{~m} \text { ) }\end{array}$ & $\begin{array}{l}\text { Defined as frail if any of the } 4 \text { scales deemed } \\
\text { patient as frail }\end{array}$ \\
\hline Green, 2012 & Modified Fried Frailty Criteria & $\begin{array}{l}\text { - Slow } 15-\mathrm{m} \text { gait speed } \\
\text { - Weak dominant handgrip strength } \\
\text { - Assistance required in any of Katz Index of } \\
\text { Independence in Activities of Daily Living } \\
\text { criteria } \\
\text { - Serum albumin as a measurement of } \\
\text { malnutrition }\end{array}$ & $\begin{array}{l}\text { Defined frailty as a score }>5 \text { on a scale from } 0 \text { - } \\
12 \text { where a higher score equated to more frail } \\
\text { For gait speed, grip strength, and serum } \\
\text { albumin, based on which quartile a patient } \\
\text { was in, a value of } 0-3 \text { was given for each } \\
\text { quartile in descending order. For activities of } \\
\text { daily living, } 0 \text { points were given for } \\
\text { independent and } 3 \text { for dependent }\end{array}$ \\
\hline Stortecky, 2012 & $\begin{array}{l}\text { Modified Multidimensional } \\
\text { Geriatric Assessment }\end{array}$ & $\begin{array}{l}\text { - MMSE showing cognitive impairment } \\
\text { - MNA shows malnutrition } \\
\text { - TUG showing limitation of mobility } \\
\text { - BADL and instrumental activities of daily } \\
\text { living showed an activity with limitation } \\
\text { - Preclinical mobility disability defined as } \\
\text { decreased frequency of walking } 200 \mathrm{~m} \text { and/ } \\
\text { or climbing stairs in preceding } 6 \mathrm{mo}\end{array}$ & $\begin{array}{l}\text { Defined frailty as } \geq 3 \text { points, } \\
2 \text { points if MMSE }<21, \\
1 \text { point if MMSE } \geq 21 \text { and }<27 \text {, MNA }<12 \text {, } \\
\text { TUG } \geq 20 \text { sec, BADL with at least } 1 \text { limited } \\
\text { activity, instrumental activities of daily } \\
\text { living with at least } 1 \text { limited activity, } \\
\text { preclinical mobility disability }\end{array}$ \\
\hline $\begin{array}{l}\text { Schoenenberger, } \\
2013\end{array}$ & $\begin{array}{l}\text { Modified Geriatric Baseline } \\
\text { Examination }\end{array}$ & $\begin{array}{l}\text { - MMSE showing cognitive impairment } \\
\text { - MNA shows malnutrition } \\
\text { - TUG showing limitation of mobility } \\
\text { - BADL and instrumental activities of daily } \\
\text { living showed an activity with limitation } \\
\text { - Preclinical mobility disability defined as } \\
\text { decreased frequency of walking } 200 \mathrm{~m} \text { and/ } \\
\text { or climbing stairs in preceding } 6 \mathrm{mo}\end{array}$ & $\begin{array}{l}\text { Defined frailty as } \geq 3 \text { points, } \\
2 \text { points if } \mathrm{MMSE}<21, \\
1 \text { point if } \mathrm{MMSE} \geq 21, \text { and }<27, \text { MNA }<12, \\
\text { TUG } \geq 20 \mathrm{sec}, \text { BADL with at least } 1 \text { limited } \\
\text { activity, instrumental activities of daily } \\
\text { living with at least } 1 \text { limited activity, } \\
\text { preclinical mobility disability }\end{array}$ \\
\hline
\end{tabular}

$C A F$, Comprehensive Assessment of Frailty; CHS, Cardiovascular Health Study; MSSA, MacArthur Study of Successful Aging; MMSE, Mini Mental State Exam; MNA, Mini Nutritional Assessment; TUG, Timed Up and Go test; $B A D L$, basic activities of daily living.

sarcopenia to the frailty syndrome. ${ }^{18,19,21}$ We speculate that physical function tests and sarcopenia measurements, which seem to be significant in frailty assessments, may have a potential role in risk assessments for cardiac surgery and should be an area of further research. Significant measurements could potentially be incorporated into existing operative risk assessments, such as the EuroSCORE and STS risk score, allowing better 
TABLE 4. Associations reported within included studies

\begin{tabular}{|c|c|c|}
\hline First author, year & Association & $\begin{array}{l}\text { Odds ratio }(\mathrm{OR}) \text { or hazard ratio }(\mathrm{HR}) \\
\text { and } 95 \% \text { confidence interval }(\mathrm{CI})\end{array}$ \\
\hline \multirow[t]{3}{*}{ Lee, 2010} & After cardiac surgery, frailty is associated with in-hospital mortality & OR, $1.8 ; 95 \% \mathrm{CI}, 1.1-3.0$ \\
\hline & After cardiac surgery, frailty is associated with prolonged institutional care & OR, 6.3; 95\% CI, 4.2-9.4 \\
\hline & After cardiac surgery, frailty is associated with midterm mortality & HR, $1.5 ; 95 \%$ CI, $1.1-2.2$ \\
\hline Sundermann, 2011 & Frailty is associated with $1-y$ mortality after cardiac surgery & OR, $1.097 ; 95 \%$ CI, $1.038-1.160$ \\
\hline Afilalo, 2012 & $\begin{array}{l}\text { Frailty as measured through gait speed is associated with mortality or major morbidity } \\
\text { after coronary artery bypass graft and/or valve surgery }\end{array}$ & OR, $2.63 ; 95 \%$ CI, $1.17-5.90$ \\
\hline Green, 2012 & Frailty is associated with increased $1-y$ mortality after transcatheter aortic valve repair & HR, 3.16; 95\% CI, 1.33-7.51 \\
\hline Stortecky, 2012 & $\begin{array}{l}\text { Frailty is associated with increased all-cause mortality } 1-y \text { after transcatheter aortic } \\
\text { valve implantation } \\
\text { Frailty is associated with increased major adverse cardiac and cerebrovascular events } \\
1 \text { y after transcatheter aortic valve implantation }\end{array}$ & $\begin{array}{l}\text { OR, } 3.68 ; 95 \% \text { CI, } 1.21-11.19 \\
\text { OR, } 4.89 ; 95 \% \text { CI, } 1.64-14.60\end{array}$ \\
\hline Schoenenberger, 2013 & $\begin{array}{l}\text { After transcatheter aortic valve implantation, frailty is associated with functional } \\
\text { decline } \\
\text { After transcatheter aortic valve implantation, frailty is associated functional decline or } \\
\text { death }\end{array}$ & $\begin{array}{l}\text { OR, } 3.31 ; 95 \% \text { CI, } 1.21-9.03 \\
\text { OR, } 4.46 ; 95 \% \text { CI, } 1.85-10.75\end{array}$ \\
\hline
\end{tabular}

preoperative risk stratification of patients. In addition, protocols need to adopt scoring systems for evaluating frailty that do not exclude patients who cannot complete the performance measures. In other settings, nonperformance of performance measures, as well as inability or unwillingness to undertake the test, is associated with worse outcomes. ${ }^{22}$

There is clinical and research relevance to the findings of our systematic review. Health care systems will have to plan for the large increase in aging among the world's population. Evidence to support this includes an estimate that by the year 2050 the population of those aged 65 years will grow to 2 billion. ${ }^{10}$ It is important to note that heart failure is the leading cause of hospitalization in those aged $\geq 65$ years. ${ }^{23}$ In addition, frailty has been found to be quite prevalent among community-dwelling adults with heart failure and could play a role in heart failure development and management. $^{23}$ Interestingly, obese patients with heart failure fair better then leaner patients with heart failure, including those who are frail and cachectic, despite obesity being a major risk factor for coronary heart disease and hypertension, 2 of the most compelling risk factors for heart failure. $^{24}$ This obesity paradox, as it is described, likely has many potential mechanisms. Relating to frailty, 1 explanation for this paradox is that patients who experience weight loss are at a very high risk for developing frailty, whereas obese patients have a lesser but still significant risk. ${ }^{25}$ Obese patients have more metabolic reserve, and combined with the lower rate of frailty, can likely cope better with the catabolic effects of heart failure. ${ }^{24}$

The syndrome of frailty is important from a cardiac rehabilitation perspective because cardiac rehabilitation programs can help to increase normal functional abilities, as well as improve psychosocial well-being and exercise capacity. ${ }^{26}$ These rehabilitation programs seem to address some components of frailty. In addition, a study looking at cardiac patients undergoing cardiac rehabilitation and exercise training found that participants of this program had a decrease in mortality and that increased attendance led to increased positive outcomes. ${ }^{26,27}$ Elderly patients participating in cardiac rehabilitation programs can improve their level of independence as well as decrease their mortality, ${ }^{26}$ which leads to speculation that frailty is a reversible process.

Although our study establishes the importance of frailty in operative risk assessment, it also reveals the need for further studies to establish which criteria are best in deeming patients frail and are most predictive of clinical outcomes. We found significant heterogeneity in the criteria for frailty and in the ascertainment of postoperative outcomes. As such, it was not possible to meta-analyze our findings, nor compare and determine which frailty assessment is superior in evaluating elderly surgical patients. Two of the studies used the same frailty criteria ${ }^{15,16}$ but examined different postoperative outcomes (mortality vs functional decline). Nonetheless, both still showed that frailty was predictive of adverse outcomes. The Canadian study $^{2}$ compared different frailty assessments within its own study and determined gait speed to be most significant. We believe that further large, prospective studies must be done to directly compare and validate the performance of different frailty measures in the prediction of relevant clinical outcomes after cardiac surgery. ${ }^{28}$ Once an optimum frailty tool is validated, frailty and its components may help guide patient selection for surgery, as well as informing studies of pre- and postoperative interventions aimed at improving outcomes in patients at highest risk of adverse sequelae. In the absence of a widely accepted tool, the Clinical Frailty Scale (CFS) is a potentially practical instrument that could be used at bedsides. A potential practical solution 
could be the implementation of the CFS. The CFS, a tool born from a mathematical accumulation of deficit model of frailty, can function as a standardized eyeball test for determining frailty status based on a categorized, subjective clinical judgment of the evaluator and may be a reasonable first choice in making assessments. ${ }^{28}$ Frailty status according to the CFS (score $\geq 4$ ) could be an indication to a clinician that treatment should be applied.

Our study has several strengths. First, we developed a structured protocol incorporating detailed background knowledge, as well as study-specific inclusion criteria and quality assessment based on our research question. This allowed us to be stringent in reviewing and evaluating the results of our search. Second, our search strategy incorporated very broad medical subject heading terms applied to multiple electronic databases to ensure the most complete capture possible of the published literature on frailty, postoperative outcomes, and cardiac surgery. Third, we strategically cross-referenced the bibliographies of included articles in an effort to further maximize our search strategy.

Our study also has some limitations. First, our search strategy included only English language studies and it is possible that relevant non-English publications were missed. Second, we included only published full-text journal articles. This could introduce an element of publication bias to our review, because some studies may only have been published in abstract form. Third, when choosing articles for our review, we did not include articles evaluating individual elements of frailty, but only those that included a comprehensive assessment of frailty. With significant heterogeneity in the data collection methods of the primary studies used, it is difficult to ascertain which frailty measurements are superior.

\section{CONCLUSIONS}

Our systematic review demonstrated that a negative relationship exists between frailty and major adverse postoperative outcome following cardiac surgery, such that patients who are deemed frail, regardless of definition used, have a higher likelihood of experiencing mortality, morbidity, functional decline, and MACCE. Further study is needed in forming a standardized assessment of frailty and in determining which components of frailty correlate best with negative postoperative outcomes.

The authors thank Kerry Macdonald, BA, MLIS, for assisting in the literature search. The authors also thank Paul Komenda, MD, FRCPC, Nicholas Giacomantonio, MD, FRCPC, Kenneth Rockwood, MD, FRCPC, and the PREHAB study investigators for providing support.

\section{References}

1. Afilalo J, Eisenberg MJ, Morin JF, Bergman H, Monette J, Noiseux N, et al. Gait speed as an incremental predictor of mortality and major morbidity in elderly patients undergoing cardiac surgery. J Am Coll Cardiol. 2010;56: 1668-76.

2. Afilalo J, Mottillo S, Eisenberg MJ, Alexander KP, Noiseux N, Perrault LP, et al. Addition of frailty and disability to cardiac surgery risk scores identifies elderly patients at high risk of mortality or major morbidity. Circ Cardiovasc Qual Outcomes. 2012;5:222-8.

3. Green P, Woglom AE, Genereux P, Daneault B, Paradis JM, Schnell S, et al. The impact of frailty status on survival after transcatheter aortic valve replacement in older adults with severe aortic stenosis: a single-center experience. J Am Coll Cardiol Cardiovasc Interv. 2012;5:974-81.

4. Nilsson J, Algotsson L, Hoglund P, Luhrs C, Brandt J. Comparison of 19 preoperative risk stratification models in open-heart surgery. Eur Heart J. 2006; 27:867-74.

5. Barili F, Pacini D, Capo A, Rasovic O, Grossi C, Alamanni F, et al. Does EuroSCORE II perform better than its original versions? A multicentre validation study. Eur Heart J. 2013;34:22-9.

6. Puskas JD, Kilgo PD, Thourani VH, Lattouf OM, Chen E, Vega JD, et al. The society of thoracic surgeons 30-day predicted risk of mortality score also predicts long-term survival. Ann Thorac Surg. 2012;93:26-33; discussion $33-5$.

7. Wendt D, Osswald BR, Kayser K, Thielmann M, Tossios P, Massoudy P, et al. Society of Thoracic Surgeons score is superior to the EuroSCORE determining mortality in high risk patients undergoing isolated aortic valve replacement. Ann Thorac Surg. 2009;88:468-74; discussion 474-5.

8. Sundermann S, Dademasch A, Rastan A, Praetorius J, Rodriguez H, Walther T, et al. One-year follow-up of patients undergoing elective cardiac surgery assessed with the comprehensive assessment of frailty test and its simplified form. Interact Cardiovasc Thorac Surg. 2011;13:119-23.

9. Fulop T, Larbi A, Witkowski JM, McElhaney J, Loeb M, Mitnitski A, et al. Aging, frailty and age-related diseases. Biogerontology. 2010;11:547-63.

10. Clegg A, Young J, Iliffe S, Rikkert MO, Rockwood K. Frailty in elderly people. Lancet. 2013;381:752-62.

11. Afilalo J, Karunananthan S, Eisenberg MJ, Alexander KP, Bergman H. Role of frailty in patients with cardiovascular disease. Am J Cardiol. 2009; 103:1616-21.

12. Fried LP, Tangen CM, Walston J, Newman AB, Hirsch C, Gottdiener J, et al. Frailty in older adults: Evidence for a phenotype. J Gerontol A Biol Sci Med Sci. 2001;56:M146-56.

13. Ottawa Hospital Research Institute http://www.ohri.ca/programs/clinical_ epidemiology/oxford.asp. Accessed February 24, 2014.

14. Sundermann S, Dademasch A, Praetorius J, Kempfert J, Dewey T, Falk V, et al. Comprehensive assessment of frailty for elderly high-risk patients undergoing cardiac surgery. Eur J Cardiothorac Surg. 2011;39:33-7.

15. Stortecky S, Schoenenberger AW, Moser A, Kalesan B, Juni P, Carrel T, et al. Evaluation of multidimensional geriatric assessment as a predictor of mortality and cardiovascular events after transcatheter aortic valve implantation. J Am Coll Cardiol Cardiovasc Interv. 2012;5:489-96.

16. Schoenenberger AW, Stortecky S, Neumann S, Moser A, Juni P, Carrel T, et al. Predictors of functional decline in elderly patients undergoing transcatheter aortic valve implantation (TAVI). Eur Heart J. 2013;34:684-92.

17. Lee DH, Buth KJ, Martin BJ, Yip AM, Hirsch GM. Frail patients are at increased risk for mortality and prolonged institutional care after cardiac surgery. Circulation. 2010;121:973-8.

18. Viana JU, Silva SL, Torres JL, Dias JM, Pereira LS, Dias RC. Influence of sarcopenia and functionality indicators on the frailty profile of communitydwelling elderly subjects: a cross-sectional study. Braz J Phys Ther. 2013;17: 373-81.

19. Roubenoff R. Sarcopenia and its implications for the elderly. Eur J Clin Nutr. 2000;54(Suppl 3):S40-7.

20. Carter CS, Marzetti E, Leeuwenburgh C, Manini T, Foster TC, Groban L, et al. Usefulness of preclinical models for assessing the efficacy of latelife interventions for sarcopenia. J Gerontol A Biol Sci Med Sci. 2012;67: $17-27$.

21. Marzetti E, Leeuwenburgh C. Skeletal muscle apoptosis, sarcopenia and frailty at old age. Exp Gerontol. 2006;41:1234-8.

22. Rockwood K, Jones D, Wang Y, Carver D, Mitnitski A. Failure to complete performance-based measures is associated with poor health status and an increased risk of death. Age Ageing. 2007;36:225-8.

23. McNallan SM, Singh M, Chamberlain AM, Kane RL, Dunlay SM, Redfield MM, et al. Frailty and healthcare utilization among patients with heart failure in the community. J Am Coll Cardiol Heart Fail. 2013;1:135-41. 
24. Lavie CJ, De Schutter A, Alpert MA, Mehra MR, Milani RV, Ventura HO. Obesity paradox, cachexia, frailty, and heart failure. Heart Fail Clin. 2014;10: 319-26.

25. Strandberg TE, Stenholm S, Strandberg AY, Salomaa VV, Pitkala KH, Tilvis RS. The "obesity paradox," frailty, disability, and mortality in older men: a prospective, longitudinal cohort study. Am J Epidemiol. 2013;178: 1452-60.
26. Menezes AR, Lavie CJ, Milani RV, Forman DE, King M, Williams MA. Cardiac rehabilitation in the United States. Prog Cardiovasc Dis. 2014;56:522-9.

27. Suaya JA, Stason WB, Ades PA, Normand SL, Shepard DS. Cardiac rehabilitation and survival in older coronary patients. J Am Coll Cardiol. 2009;54:25-33.

28. Rockwood K, Song X, MacKnight C, Bergman H, Hogan DB, McDowell I, et al A global clinical measure of fitness and frailty in elderly people. Can Med Assoc J. 2005;173:489-95

\title{
EDITORIAL COMMENTARY
}

\section{Frailty: It's hard to define, but you know it when you see it}

\author{
Keith B. Allen, MD
}

See related article on pages 3110-7.

In their article in this issue of the Journal entitled, "The impact of frailty on outcomes after cardiac surgery: A systematic review," Sepehri and colleagues ${ }^{1}$ analyze the influence that "frailty" has on predicting poor outcomes after cardiac surgery. In their review of 6 contemporary, prospective studies published during the last 4 years and encompassing more than 4500 patients, Sepehri and colleagues ${ }^{1}$ conclude, not surprisingly, that patients deemed frail by an objective assessment tool have a higher likelihood of mortality, morbidity, functional decline, and major adverse cardiac and cerebrovascular events after cardiac surgery, regardless of how frailty is defined. Sepehri and colleagues $^{1}$ are to be complimented for highlighting the adverse impact that frailty has on cardiac surgical outcomes; however, a key question is whether the concept of frailty is based on a matrix of several standardized tests or there is one test alone that would be most predictive. To paraphrase former Supreme Court Justice Potter Stewart, frailty is hard to define but I know it when I see it.

Current risk models either overestimate (euroSCORE) or underestimate (Society of Thoracic Surgeons) perioperative risk; discrepancies between predicted and observed outcomes may be confounded by a disproportionate weight placed on chronologic age alone without taking into account the biology of the aged. Advanced age is not necessarily synonymous with vulnerability to adverse health

\footnotetext{
From the Department of Cardiothoracic and Vascular Surgery, St Luke's Mid America Heart Institute, Kansas City, Mo.

Disclosures: Author has nothing to disclose with regard to commercial support.

Received for publication Sept 30, 2014; accepted for publication Oct 1, 2014

Address for reprints: Keith B. Allen, MD, 4320 Wornall Rd, Medical Plaza II, Suite

50, Kansas City, MO 64111 (E-mail: kallen2340@aol.com).

J Thorac Cardiovasc Surg 2014;148:3117-8

$0022-5223 / \$ 36.00$

Copyright (C) 2014 by The American Association for Thoracic Surgery

http://dx.doi.org/10.1016/j.jtcvs.2014.10.013
}

outcomes; furthermore, the potential to use age alone inappropriately to ration increasingly expensive and technologically advanced health care, such as transcatheter aortic valve replacement, has made the concept of frailty very timely. In surgical parlance, frailty is an ambiguous but well understood phrase that encompasses a patient's inability to withstand and successfully recovery from surgery. Surgeons, whether consciously or unconsciously, have always evaluated frailty. Watching the patient get out of bed and walk across the room and testing the firmness of the handshake are all part of a seasoned surgeon's "eyeball" test for frailty. Of the 6 studies in this systematic review, 5 incorporated a physical function assessment as part of the determination of frailty, including hand grip strength, timed get up and go test, and gait speed. Although Sepehri and colleagues ${ }^{1}$ were unable to determine which frailty test is best, it's clear from their review that a more "standardized eyeball" test, such as the Clinical Frailty Scale, may better predict postoperative outcomes.

Although standardized frailty scores may be predictive of poor surgical outcomes, the use of them to justify lessinvasive procedures with the hope of achieving better outcomes may be misguided. It is clear that frailty predicts worse outcomes with either surgical or nonsurgical procedures (frail patients have worse outcomes than nonfrail patients even without subjecting them to a procedure). The critical question that needs to be asked is this: Does frailty identify a group of patients who would derive preferential benefit from one or another form of treatment? Within the review of Sepehri and colleagues, ${ }^{1}$ patients labeled as frail had a higher hazard ratio for death when undergoing less-invasive procedures, such as transcatheter aortic valve replacement, than when undergoing moreinvasive open procedures. Given the same frailty definition within each study, one would expect to be able to perform less-invasive procedures on more frail patients and have better outcomes-not worse. This paradox might be 